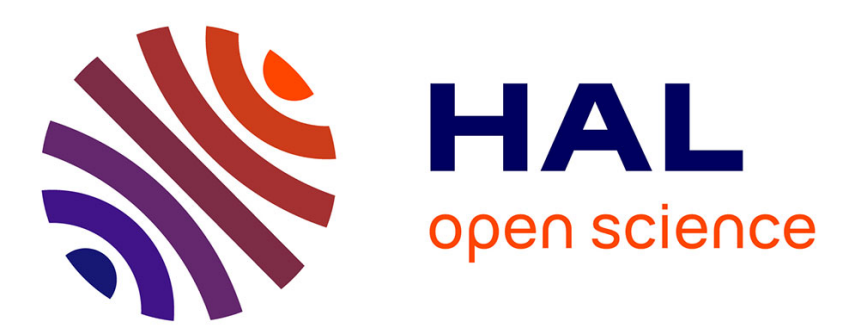

\title{
Radicals generated in alternating guanine-cytosine duplexes by direct absorption of low-energy UV radiation $\dagger$
}

Akos Banyasz, Lara Martinez-Fernandez, Roberto Improta, Tiia-Maaria Ketola, Clémence Balty, Dimitra Markovitsi

\section{To cite this version:}

Akos Banyasz, Lara Martinez-Fernandez, Roberto Improta, Tiia-Maaria Ketola, Clémence Balty, et al.. Radicals generated in alternating guanine-cytosine duplexes by direct absorption of low-energy UV radiation $\dagger$. Physical Chemistry Chemical Physics, 2018, 20, pp.21381. 10.1039/c8cp02588f . cea-02328415

\section{HAL Id: cea-02328415 https://hal-cea.archives-ouvertes.fr/cea-02328415}

Submitted on 23 Oct 2019

HAL is a multi-disciplinary open access archive for the deposit and dissemination of scientific research documents, whether they are published or not. The documents may come from teaching and research institutions in France or abroad, or from public or private research centers.
L'archive ouverte pluridisciplinaire HAL, est destinée au dépôt et à la diffusion de documents scientifiques de niveau recherche, publiés ou non, émanant des établissements d'enseignement et de recherche français ou étrangers, des laboratoires publics ou privés. 
Check for updates

Cite this: Phys. Chem. Chem. Phys., 2018, 20, 21381

Received 23rd April 2018 Accepted 26th July 2018

DOI: $10.1039 / c 8 c p 02588 f$

rsc.li/pccp

\section{Radicals generated in alternating guanine-cytosine duplexes by direct absorption of low-energy UV radiation $\dagger$}

\author{
Akos Banyasz, (D) a Lara Martínez-Fernández, (D) a Roberto Improta, (D) *ab \\ Tiia-Maaria Ketola, ${ }^{a}$ Clémence Balty ${ }^{a}$ and Dimitra Markovitsi iD *a
}

\begin{abstract}
Recent studies have evidenced that oxidatively damaged DNA, which potentially leads to carcinogenic mutations and aging, may result from the direct absorption of low-energy photons (>250 nm). Herein, the primary species, i.e., ejected electrons and base radicals associated with such damage in duplexes with an alternating guanine-cytosine sequence are quantified by nanosecond transient absorption spectroscopy. The one-photon ionization quantum yield at $266 \mathrm{~nm}$ is $1.2 \times 10^{-3}$, which is similar to those reported previously for adenine-thymine duplexes. This means that the simple presence of guanine, the nucleobase with the lowest ionization potential, does not affect photo-ionization. The transient species detected after $3 \mu$ s are identified as deprotonated guanine radicals, which decay with a half-time of $2.5 \mathrm{~ms}$. Spectral assignment is made with the help of quantum chemistry calculations (TD-DFT), which for the first time, provide reference absorption spectra for guanine radicals in duplexes. In addition, our computed spectra predict the changes in transient absorption expected for hole localization as well as deprotonation (to cytosine and bulk water) and hydration of the radical cation.
\end{abstract}

\section{Introduction}

Oxidatively damaged DNA is an important concern for health because of its correlation with the appearance of carcinogenic mutations and aging. One of the factors inducing such damage is UV radiation. It is well established that high-energy UV photons provoke photo-ionization of nucleic acids, generating radicals which are precursors to oxidative damage. ${ }^{1}$ In contrast, the action of low-energy photons is commonly considered to necessitate the mediation of other molecules, which absorb light and subsequently react with DNA. ${ }^{2}$ As a matter of fact, nucleobases, the only DNA components that absorb photons with wavelengths longer than $230 \mathrm{~nm}$ (5.4 eV; Fig. 1a), even extending to the UVA domain, ${ }^{3,4}$ are not expected to undergo photo-ionization because their ionization potential is higher than $7 \mathrm{eV} .^{5}$

During the past decade, a few studies performed on short oligonucleotides using laser spectroscopy have questioned the above-described observations. ${ }^{6-8}$ However, significant advancement was made recently from the discovery that the irradiation of purified

\footnotetext{
${ }^{a}$ LIDYL, CEA, CNRS, Université Paris-Saclay, F-91191 Gif-sur-Yvette, France. E-mail: dimitra.markovitsi@cea.fr

${ }^{b}$ Istituto Biostruture e Bioimmagini-Consiglio Nazionale delle Ricerche, Via Mezzocannone 16, I-80134 Napoli, Italy. E-mail: robimp@unina.it $\dagger$ Electronic supplementary information (ESI) available: Fig. ESI-1. See DOI: 10.1039/ c8cp02588f
}

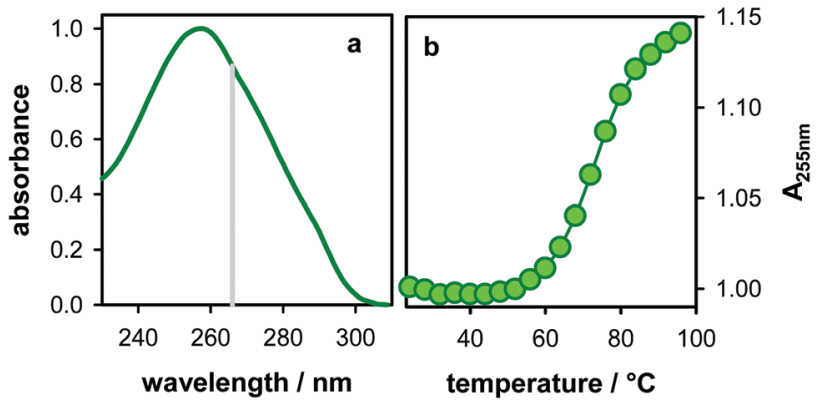

Fig. 1 Normalized absorption spectrum (a) and melting curve (b) of $\mathrm{GC}_{5}$ in phosphate buffer. The grey vertical line in (a) corresponds to the wavelength of laser excitation.

genomic DNA in solution at 254 and $295 \mathrm{~nm}$ produces the wellknown oxidation marker 8-oxo-7,8-dihydro-2'-deoxyguanosine (8-oxodGuo) via a mechanism involving guanine radical cations. ${ }^{9}$ Similarly, 8-oxodGuo was detected upon irradiation of telomeric G-quadruplexes at $266 \mathrm{~nm} .{ }^{10} \mathrm{~A}$ key point in these two studies is the use of a continuous light source, thus ruling out two-photon ionization, which usually interferes in the case of short light pulses. These findings prompted us to pursue our photo-ionization study of model DNA duplexes, initiated in $2006,{ }^{7}$ by improving our approach. ${ }^{10-12}$

Our main tool is nanosecond transient absorption spectroscopy with $266 \mathrm{~nm}$ excitation. We apply experimental protocols 
specifically developed to minimize and control two-photon effects. ${ }^{12}$ We quantitatively characterize the primary species, i.e., ejected electrons and base radicals and examine how the base sequence and secondary structure affect this process. In parallel to the experimental study, we carry out quantum chemistry calculations (TD-DFT), which are valuable for the characterization of base radicals. In the case of monomeric species, the absorption spectra of radicals are well identified. ${ }^{11,13-15}$ However, in the case of DNA multimers, the radical spectra have to be assessed since they may be affected by sequence and secondary structure because of electronic interactions among bases.

So far, we studied duplexes composed exclusively of adeninethymine base pairs. Their propensity to undergo one-photon ionization was found to be lower than that of telomeric G-quadruplexes. ${ }^{10-12}$ The major constituent of the latter fourstranded structures is guanine, the nucleobase with the lowest ionization potential. ${ }^{5}$ To obtain the first insight into oxidatively generated damage upon direct absorption of UV radiation by guanine-containing duplexes, herein, we focus on systems with alternating guanine-cytosine sequences, which are abbreviated as $\mathrm{GC}_{n}$.

The experimental part of our study is performed for a duplex with ten base pairs, $\mathrm{GC}_{5}$, and its behaviour is compared to that previously reported for an alternating adenine-thymine duplex $\left(\mathrm{AT}_{10}\right) .{ }^{12}$ Our choice of shorter oligomers in the present study is motivated by the possibility of preparing duplexes with better quality by annealing, which is impossible for $\mathrm{GC}_{10}$. Although $\mathrm{GC}_{5}$ is shorter than the $\mathrm{AT}_{10}$ duplex, it melts at a higher temperature, i.e., $70{ }^{\circ} \mathrm{C}$ (Fig. 1b) vs. $52{ }^{\circ} \mathrm{C},{ }^{12}$ thus showing higher stability.

In our theoretical calculations, we consider the model duplex $\mathrm{GC}_{1}$ with two base pairs (Fig. 2b). Its properties are compared to those of $2^{\prime}$-deoxyguanosine $5^{\prime}$-monophosphate, dGMP, and the guanine-cytosine Watson-Crick pair, i.e., G:C formed by the corresponding nucleotides. We determine the absorption spectra of the guanine radical cation and the radicals resulting from its deprotonation either towards the aqueous solvent or cytosine with which it is paired (Fig. 2a). ${ }^{16,17}$ In addition, we compute the spectra of the 8-hydroxy-7,8-dihydroguanyl radical $\left(8-\mathrm{OH}-\mathrm{G}^{\bullet}\right)$, which is considered to lead to the formation of 8 -oxo-7,8-dihydroguanine (8-oxoG). ${ }^{18,19}$ Although numerous reactions involving guanine radicals are reported in the literature, ${ }^{18,20-22}$ we focus specifically on $8-\mathrm{OH}-\mathrm{G}^{\bullet}$ because it could interfere with the radical spectra. ${ }^{23}$

\section{Methodological details}

\section{Experiments}

Spectroscopic measurements. Transient absorption measurements were obtained using a homemade setup. Excitation pulses ( $5 \mathrm{~ns}$ at $266 \mathrm{~nm}$ ) were obtained as the fourth harmonic of an Nd:YAG laser (Spectra-Physics, Quanta Ray) operating at $10 \mathrm{~Hz}$. The pulse energy was measured by an NIST traced pyroelectric sensor (OPHIR Nova2/PE25). The excited area at the surface of the sample was $0.06 \mathrm{~cm}^{2}$, and the optical path-length on the excitation side was $0.1 \mathrm{~cm}$. The analysing beam (150 W Xe-arc lamp, Applied Photophysics) was passed through the sample (optical length $1 \mathrm{~cm}$ ) at a right angle with respect to the exciting beam; it was dispersed in an SPEX 270M monochromator and was detected by a Hamamatsu R928 photomultiplier. The signal from the photomultiplier was recorded by a Lecroy Waverunner 6050 oscilloscope. Detection on the sub-microsecond time-scale was achieved by intensifying the emission intensity of the Xe-arc lamp via an electric discharge.

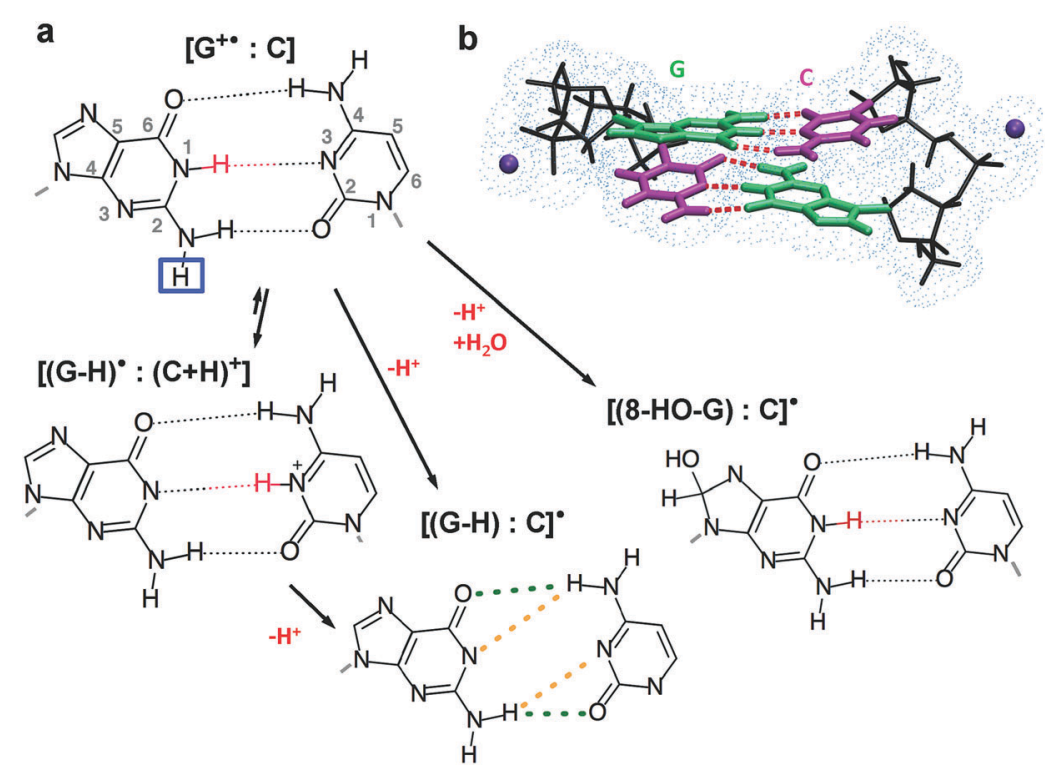

Fig. 2 (a) Possible mechanisms for the deprotonation and hydration of the guanine cation in a guanine-cytosine Watson-Crick pair; orange dashes indicate possible rearrangement of the hydrogen bonds. Removal of the hydrogen atom framed in blue corresponds to formation of the $\left[\left(\mathrm{G}-\mathrm{H}_{2}\right): \mathrm{C}\right]$ radical. (b) $\mathrm{GC}_{1}$ model duplex used in the calculations; guanines are represented in green, cytosines in pink, backbones in black, hydrogen bonds in red, and $\mathrm{Na}^{+}$counter-ions in purple. Blue points depict the cavity of the solvent, which is treated as a continuum. 
To minimize sample exposure and reduce the excitation frequency to $0.2 \mathrm{~Hz}$, fast shutters were placed in the path of both the laser and lamp beams. A wavelength-by-wavelength approach was followed for the construction of the transient absorption spectra. Typically, at each wavelength, a series of three successive signals, resulting from 100-200 laser shots each, were recorded; if judged to be reproducible, they were averaged to reduce the signal-to-noise ratio. Steady-state absorption spectra were recorded using a Lambda 900 (Perkin-Elmer) spectrophotometer.

Oligonucleotide handling. Oligonucleotides were purchased from Eurogentec Europe as single strands; they were purified by HPLC, and their quality was tested by MALDI-TOF measurements. They were dissolved in phosphate buffer $\left(0.15 \mathrm{~mol} \mathrm{~L}^{-1} \mathrm{NaH}_{2} \mathrm{PO}_{4}\right.$, $0.15 \mathrm{~mol} \mathrm{~L}^{-1} \mathrm{Na}_{2} \mathrm{HPO}_{4}$ ) prepared with ultrapure water delivered by a MILLIPORE (Milli-Q Synthesis) system. The $\mathrm{pH}$ was adjusted to 7 by the addition of concentrated $\mathrm{NaOH}$ solution. Duplexes were prepared in a dry bath (Eppendorf-ThermoStatplus). Two $\mathrm{mL}$ of concentrated oligomer solution was heated to $96{ }^{\circ} \mathrm{C}$ for $5 \mathrm{~min}$ and cooled to $72{ }^{\circ} \mathrm{C}$ (cooling time: $\sim 1 \mathrm{~h}$ ), where the temperature was maintained for 30 minutes; subsequently, the solution was cooled to $4{ }^{\circ} \mathrm{C}$ (cooling time: $\sim 2 \mathrm{~h}$ ), where it was incubated overnight. A typical melting curve is shown in Fig. 1b. For the detection of hydrated electrons on the sub- $\mu$ s scale, $2 \mathrm{~mL}$ of argon-saturated solution, contained in $1 \mathrm{~cm} \times 1 \mathrm{~cm}$ quartz cell, was mildly stirred during the experiment; fresh samples were used for each excitation intensity. For recording transient signals at longer times, two type of quartz cells containing $2.5 \mathrm{~mL}$ of solution and a flow system allowing the circulation of $40 \mathrm{~mL}$ of solution were used. In all cases, the optical density on the excitation side was $0.25 \pm$ 0.02 over $0.1 \mathrm{~cm}$. For measurements at times longer than $2 \mu \mathrm{s}$, a

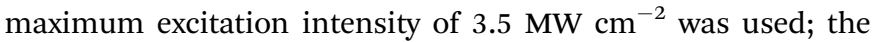
concentration of detected ejected electrons was $4 \times 10^{-7} \mathrm{~mol} \mathrm{~L}^{-1}$, which was about two orders of magnitude lower than the duplex concentration. During the experiments the samples were kept at $23 \pm 0.5{ }^{\circ} \mathrm{C}$.

As mentioned in our previous studies, ${ }^{10,24}$ the transient absorption signals of purine radicals are not affected by the presence of oxygen (intensity changes $<10 \%$ ). As a matter of fact, hydrated electrons are scavenged by the phosphate groups of the buffer, which are deliberately present in high concentration. Thus, their reaction with oxygen is minimized.

\section{Computations}

Our study was performed for three different model systems, dGMP, G:C and $\mathrm{GC}_{1}$, including the 2-deoxyribose groups and counter ions at a full quantum mechanical (QM) level. The ground state minima of the neutral systems and of those containing a radical cation or a deprotonated radical were optimized by means of density functional theory (DFT). Then, the corresponding absorption spectra were computed using the time-dependent version of DFT (TD-DFT).

For optimization of the minima and computation of the spectra we used the M052X functional ${ }^{25}$ and the 6-31G(d) basis set. This level of theory was selected because it is known to provide accurate results for both stacked ${ }^{25}$ and guanine-cytosinecontaining systems. ${ }^{26-31}$ Moreover, it allows a comparison with results obtained previously for radicals in telomeric G-quadruplexes and $\mathrm{AT}_{10}{ }^{10,12}$ For $\mathrm{G}: \mathrm{C}$ and $\mathrm{GC}_{1}$, bulk solvent effects were included implicitly by the Polarizable Continuum Model (PCM). ${ }^{32,33}$ A mixed explicit/implicit model, considering five water molecules quantum mechanically, was used for dGMP. All calculations were performed with the Gaussian09 program. ${ }^{34}$ For easier comparison with the experimental spectra, each transition was convoluted using a Gaussian function with a half width at half maximum of $0.30 \mathrm{eV}$ after being red-shifted by $0.6 \mathrm{eV}$. This shift accounts for all sources of inaccuracy in our calculations (basis set size, lack of vibrational/thermal effects and functional). ${ }^{35}$

\section{Results}

\section{Experiments}

At $30 \mathrm{~ns}$, which corresponds to the time-resolution of our experimental setup, electrons stemming from DNA photoionization are expected to be completely hydrated, thus exhibiting a broad absorption spectrum around $700 \mathrm{~nm} .{ }^{36}$ The transient absorption signals recorded for $\mathrm{GC}_{5}$ at this wavelength decay in less than $3 \mu \mathrm{s}$; an example is shown in Fig. 3a. They are fitted with a mono-exponential function $c+\Delta A_{0} \exp (-t / \tau)$. The time constants, $\tau$, derived from the fits of the signals obtained at various excitation intensities are significantly longer $(0.60 \pm 0.02 \mu \mathrm{s})$ than those found for previously studied DNA models $(0.4 \pm 0.1 \mu \mathrm{s}) \cdot{ }^{10-12}$ We checked that this discrepancy does not arise from the contribution of base radicals to the transient absorption. Indeed, when the solution is purged by $\mathrm{N}_{2} \mathrm{O}$, which is a very efficient scavenger for hydrated electrons, ${ }^{37}$ the signal is too weak to draw any clear conclusion.

The $\Delta A_{0}$ value combined with the maximum molar absorption coefficient $\left(19700 \mathrm{~cm}^{-1}\right)^{36}$ gives the initial concentration of hydrated electrons $[\mathrm{e}]_{0}$, which is used for the determination of the photo-ionization quantum yields. Fig. $3 \mathrm{~b}$ shows the so-called ionization curve of $\mathrm{GC}_{5}$ together with that reported previously for $\mathrm{AT}_{10}{ }^{12}$ Also, $[\mathrm{e}]_{0}$ varies as a function of the concentration of absorbed photons $[h \nu]$ according to the equation $[\mathrm{e}]_{0}=\phi_{1 h \nu}[h \nu]+$ $\phi_{2 h \nu}[h \nu]^{2}$, where $\phi_{1 h \nu}$ and $\phi_{2 h \nu}$ represent the yields of one- and two-photon processes, respectively. The experimental points are fitted with linear functions. The intercept provides $\phi_{1 h \nu}$, whereas
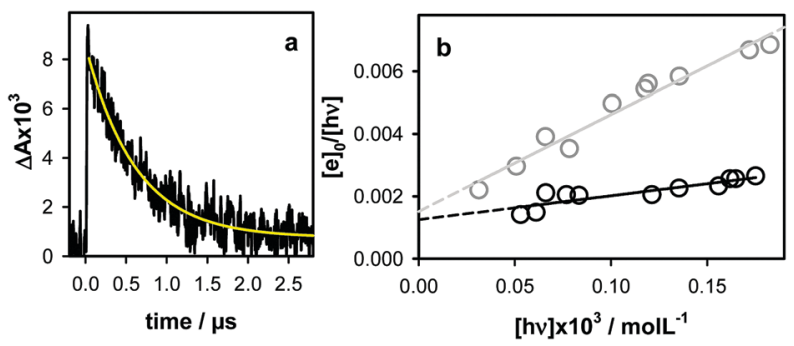

Fig. 3 (a) Transient absorption decay recorded at $700 \mathrm{~nm}$ for an argonsaturated $\mathrm{GC}_{5}$ solution (black) with an excitation intensity of $3.5 \mathrm{MW} \mathrm{cm}^{-2}$; the yellow line corresponds to the fit with a mono-exponential function.

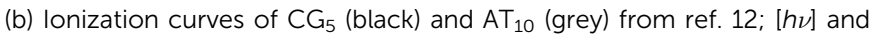
$[e]_{0}$ denote the concentration of absorbed photons and hydrated electrons at time zero, respectively; experimental points (circles) are fitted with linear functions (solid lines). 
the slope is correlated with $\phi_{2 h \nu}$. The one-photon ionization quantum yield of $\mathrm{GC}_{5}$ is $(1.2 \pm 0.2) \times 10^{-3}$, which is quite similar to that found for alternating $\operatorname{AT}_{10}(1.5 \pm 0.3) \times 10^{-3} \cdot{ }^{12} \mathrm{In}$ contrast, an important difference is observed for the $\phi_{2 h \nu}$ values, which are 4 times smaller in the case of $\mathrm{GC}_{5}$.

After $3 \mu \mathrm{s}$, when the hydrated electrons have decayed, the fingerprint of DNA radicals can be observed. The signals obtained in the visible spectral domain remain constant for about $120 \mu \mathrm{s}$, and they decay on the ms time-scale; the signals recorded at $500 \mathrm{~nm}$ are presented in Fig. 4 as an example. The decay is fitted with the sum of two exponential functions. However, the time constants derived from the fit depend on the considered time-window and are sensitive to weak baseline fluctuations. In contrast, the half time of the signals is relatively reproducible: $2.5 \pm 0.2 \mathrm{~ms}$. At $20 \mathrm{~ms}$, the transient absorption decays to about $10 \%$ of its initial value. At longer times, the signals are too weak $\left(\Delta A<0.5 \times 10^{-4}\right)$, precluding reliable fits.

The spectra determined at $100 \mu \mathrm{s}$ and $1 \mathrm{~ms}$ exhibit an absorption band peaking at $310 \mathrm{~nm}$ and a less intense band at around $400 \mathrm{~nm}$ (Fig. 5a). In addition, we observe a large, rather flat absorption band at around $500 \mathrm{~nm}$, which is accompanied by an important long-persisting red tail. At $20 \mathrm{~ms}$, the two UV bands are still present, but the transient absorbance in the visible domain becomes too weak to be properly detected. The spectra of G-quadruplexes recorded on a similar time-scale undergo important transformations, ${ }^{10}$ but those of $\mathrm{GC}_{5}$ do not indicate any clear change beyond the experimental errors. Consequently, we conclude that the presence of either a unique
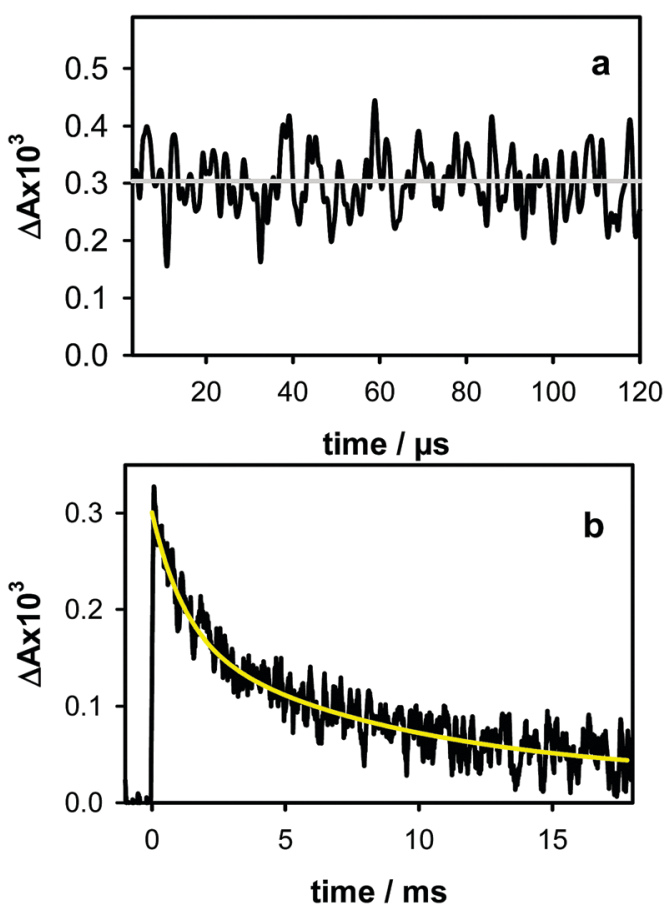

Fig. 4 Transient absorption signals recorded for $\mathrm{GC}_{5}$ at $500 \mathrm{~nm}$ (black). The grey line in (a) indicates the average $\Delta A$ value between 3 and $120 \mu$, whereas the yellow line in (b) corresponds to the fit with the sum of two exponential functions (time constants: 1.2 and $8.7 \mathrm{~ms}$ ).

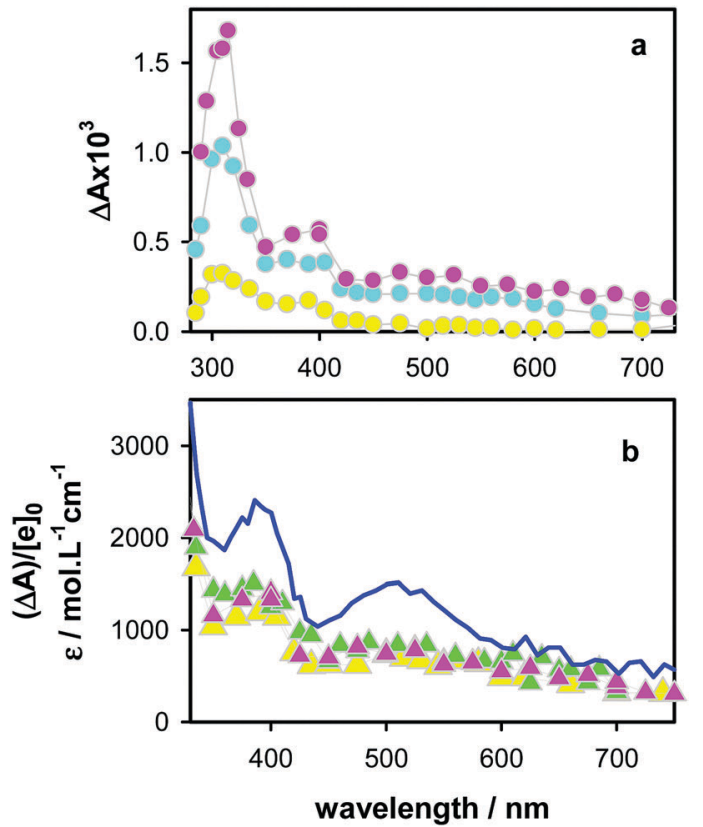

Fig. 5 (a) Time-resolved spectra determined for $\mathrm{GC}_{5}$ at $100 \mu \mathrm{s}$ (pink), $1 \mathrm{~ms}$ (cyan) and $20 \mathrm{~ms}$ (yellow). (b) Time-resolved spectra of $\mathrm{GC}_{5}$ at $100 \mu \mathrm{s}$ (triangles); different colours correspond to independent measurements performed on samples prepared with different oligonucleotide batches; the transient absorbance is divided by the concentration of ejected electrons $[e]_{0}$. The blue line corresponds to the deprotonated radical of dGMP, which is represented by its molar absorption coefficient. ${ }^{15}$

transient species or multiple species with similar absorption spectra is observed.

As deprotonation of guanine radicals in duplexes occurs on the nanosecond time-scale, ${ }^{38}$ we compare in Fig. $5 \mathrm{~b}$ the spectrum of the deprotonated dGMP radical ${ }^{15}$ with the time-resolved spectra of $\mathrm{GC}_{5}$ at $100 \mu \mathrm{s}$. We limit the comparison to wavelengths longer than $330 \mathrm{~nm}$ because at shorter ones, differential absorption spectra reflect not only radical but also ground state absorption, which is not the same for DNA monomers and DNA multimers. ${ }^{10,11}$ To better appreciate the experimental errors, the results of three independent measurements are shown in Fig. 5b. For a quantitative comparison, the differential absorbance is divided by the concentration of ejected electrons, whereas the monomer spectrum is shown with its molar absorption coefficient. Following this normalization, it appears clearly that the intensity of the duplex spectrum is about half of that of the monomer spectrum. Moreover, in contrast to that of $\mathrm{GC}_{5}$, the spectrum of the dGMP radical shows a well-defined absorption band at around $500 \mathrm{~nm}$ (Fig. 5b).

\section{Computations}

As the first step, we computed the absorption spectrum of the guanine radical cation in $\mathrm{GC}_{1}$, which is denoted as $\left[\mathrm{G}^{+\bullet}: \mathrm{C}\right]$. The $\mathrm{PCM} / \mathrm{TD}-\mathrm{M} 052 \mathrm{X}$ geometry optimizations predicted that in the most stable cationic species, the hole is localized over a single guanine base, which exhibits a geometry close to that of the typical guanine cation; the other bases have structures very similar to those found in the 'neutral' $\mathrm{GC}_{1}$. Then, we also optimized the minimum for the cationic species, which exhibited delocalization 
of the electron hole over two guanines. The energy difference between these two species was $-0.45 \mathrm{eV}\left(10 \mathrm{kcal} \mathrm{mol}^{-1}\right)$, suggesting that the guanine radical cation in $\mathrm{GC}_{1}$ is preferably localized. The absorption spectra computed for $\mathrm{GC}_{1}$ bearing an electron hole are shown in Fig. 6a together with that computed for dGMP, $\left(\mathrm{G}^{+} \bullet\right)$. The three spectra exhibited one band at around $370 \mathrm{~nm}$ (band I) and a second band at a longer wavelength (band II). Although the position and oscillator strength of band I were only slightly affected by duplex formation, a red shift was observed for band II. The red-shift was much larger in the case of hole delocalization, where the separation between bands I and II was $\sim 1 \mathrm{eV}$. Moreover, the oscillator strength of band II was higher compared with that of the spectrum of the localized cation.

Monomeric $\mathrm{G}^{+}$at neutral $\mathrm{pH}$ deprotonates by losing the proton in position 1 of guanine to the aqueous solvent, giving rise to the deprotonated radical $(\mathrm{G}-\mathrm{H})^{\bullet} \cdot{ }^{13}$ In duplex DNA, the latter process produces the $[(\mathrm{G}-\mathrm{H}): \mathrm{C}]^{\bullet}$ radical, as shown in Fig. 2a. As anticipated in the introduction, when guanine is paired to cytosine, as in $\mathrm{GC}_{1}$, cytosine may also act as a proton acceptor (Fig. 2a). The resulting radical, $\left[(\mathrm{G}-\mathrm{H})^{\bullet}:(\mathrm{C}+\mathrm{H})^{+}\right]$, has a formal positive charge on cytosine. We optimized the minima of both deprotonated species and computed their absorption spectra (Fig. 6b). The $\left[(\mathrm{G}-\mathrm{H})^{\bullet}:(\mathrm{C}+\mathrm{H})^{+}\right]$spectrum is similar to that of $(\mathrm{G}-\mathrm{H})^{\bullet}$ except for loss in intensity of bands I and II.

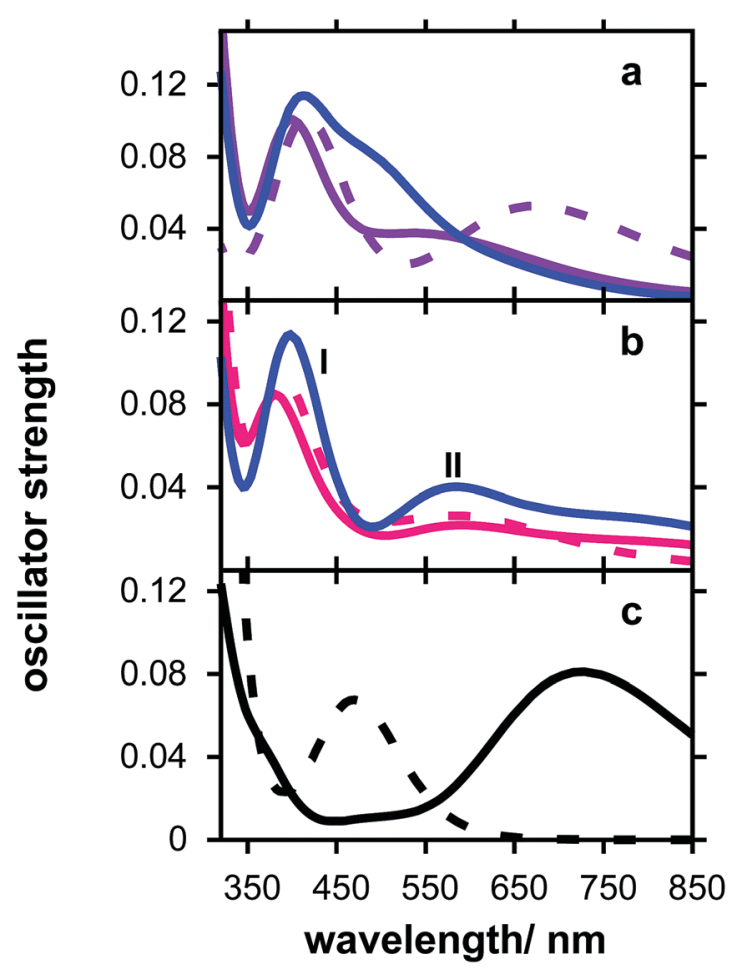

Fig. 6 Absorption spectra of the guanine radical cations (a) and deprotonated radicals ( $b$ and c) computed for dGMP (blue) and $\mathrm{GC}_{1}$. Solid and dashed purple lines in (a) correspond to the localized and delocalized duplex cations. Solid and dashed pink lines in (b) correspond to the species $[(\mathrm{G}-\mathrm{H}): \mathrm{C}]^{\bullet}$ and $\left[(\mathrm{G}-\mathrm{H})^{\bullet}:(\mathrm{C}+\right.$ $\left.\mathrm{H})^{+}\right]$illustrated in Fig. 2a. Solid and dashed lines in (c) correspond to $\left[\left(\mathrm{G}-\mathrm{H}_{2}\right): \mathrm{C}\right]^{\bullet}$ and $[(8-\mathrm{OH}-\mathrm{G}): \mathrm{C}]^{\bullet}$.
Furthermore, $\left[(\mathrm{G}-\mathrm{H})^{\bullet}:(\mathrm{C}+\mathrm{H})^{+}\right]$does not significantly absorb beyond $750 \mathrm{~nm}$. The spectrum of $[(\mathrm{G}-\mathrm{H}): \mathrm{C}]^{\bullet}$ is also similar to that described above, but band II almost disappears, becoming rather flat in the range of 550-900 nm (Fig. 6b).

The energies of the species bearing an electron hole on either guanine or cytosine are very similar. In the case of $\mathrm{G}: \mathrm{C}$, the species with the positive charge on cytosine is slightly more stable by $0.57 \mathrm{kcal} \mathrm{mol}^{-1}$. The population ratio determined according to the Boltzmann distribution is $27: 73$, which is in agreement with the estimates derived from the $\mathrm{p} K_{\mathrm{a}}$ values of the bases ${ }^{16}$ and previous theoretical studies on G:C. ${ }^{39}$ For $\mathrm{GC}_{1}$, we find a similar energy difference but in the opposite direction; the species corresponding to the guanine cation is $0.44 \mathrm{kcal} \mathrm{mol}^{-1}$ more stable and represents $67 \%$ of the population.

Deprotonation to bulk water results in the loss of the hydrogen bond connecting the nitrogen in position 1 of guanine with the nitrogen in position 3 of cytosine (Fig. 2a). This loss decreases the stability of the Watson-Crick pair, which conserves only two $\mathrm{O} \cdots \mathrm{H}$ hydrogen bonds. Consequently, rearrangement of the relative position of the $\mathrm{G}$ and $\mathrm{C}$ bases may occur, altering the nature of the remaining two bonds from $\mathrm{O} \cdots \mathrm{H}$ to $\mathrm{N} \cdots \mathrm{H}$ bonds, ${ }^{23,40}$ as indicated by the orange dashes in Fig. 2a. Our calculations show that partial base rearrangement takes place in $\mathrm{GC}_{1}$; in particular, a shift between the bases is observed. However, according to our calculations for $\mathrm{G}: \mathrm{C}$, this rearrangement does not induce important spectral changes (ESI $\dagger$ ).

We also examined deprotonation of the guanine radical cation via transfer of a proton from the $\mathrm{NH}_{2}$ group at position 2 to bulk water. The spectrum of the $\left[\left(\mathrm{G}-\mathrm{H}_{2}\right): \mathrm{C}\right]^{\bullet}$ radical is shown in Fig. 6c; it is characterized by the presence of an intense band located at significantly longer wavelengths compared to that of $[(\mathrm{G}-\mathrm{H}): \mathrm{C}]^{\bullet}$, which is consistent with the experimental spectra of monomeric analogues. ${ }^{15,41}$ The energy difference between the deprotonated radicals $[(\mathrm{G}-\mathrm{H}): \mathrm{C}]^{\bullet}$ and $\left[\left(\mathrm{G}-\mathrm{H}_{2}\right): \mathrm{C}\right]^{\bullet}$, corresponding to a proton transfer to the bulk water, is less than $0.5 \mathrm{kcal} \mathrm{mol}^{-1}$.

Finally, we considered possible hydration by a water molecule of $\left[\mathrm{G}^{+\bullet}: \mathrm{C}\right]$, giving rise to $8-\mathrm{OH}-\mathrm{G}^{\bullet}$, which is a precursor to 8 -oxoG. ${ }^{18}$ Therefore, we optimized this species within $\mathrm{GC}_{1}$ and computed its absorption spectrum (dashes in Fig. 6c): it is characterized by the presence of an absorption band located between bands I and II of the guanine radicals, and its intensity is intermediate compared to that of the latter.

Fig. 6 clearly shows that when the guanine radicals are included in the duplex, their spectra are modified. These changes are not only due to base pairing but also due to base stacking. The contribution of these two factors is illustrated in Fig. 7, which compares the spectra of $[(\mathrm{G}-\mathrm{H}): \mathrm{C}]^{\bullet}$ computed for $\mathrm{G}: \mathrm{C}$ and $\mathrm{GC}_{1}$ with that of $(\mathrm{G}-\mathrm{H})^{\bullet}$ computed for dGMP. Band I in the spectra of G:C and dGMP shows similar characteristics. In contrast, band II is much less intense in the former system, suggesting sensitivity versus base pairing. In the $\mathrm{GC}_{1}$ spectrum, band II is even less intense, but the most significant difference occurs for band I, the intensity of which is much lower than that in the other systems. These spectral modifications have the same origin as the well-known DNA hypochromism, which is related to ground state absorption. 
To better understand the origin of the spectral features in Fig. 6 and 7, we computed the electronic density difference between the excited and ground states $\left(S_{n}-S_{0}\right)$ for the most important transitions contributing to bands I and II (Fig. 8). We did not observe any dramatic change in the nature of the excited states involved in the two bands for the three systems dGMP, G:C and $\mathrm{GC}_{1}$, which explains the qualitatively similar shape of their spectra. The most significant difference between the transitions responsible for bands I and II is the antibonding and bonding character along the C4-C5 bond, resembling the

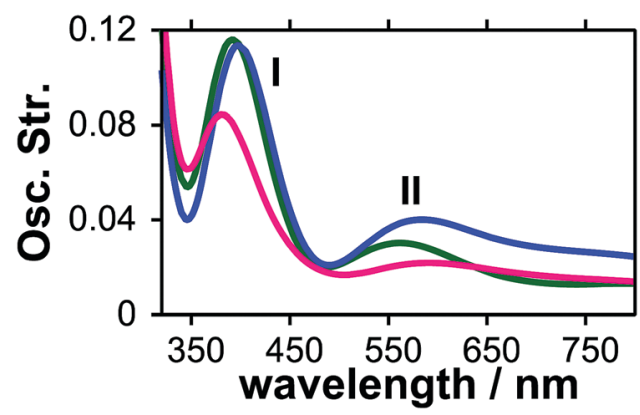

Fig. 7 Absorption spectra computed for the guanine deprotonated radical $[(\mathrm{G}-\mathrm{H}): \mathrm{C}]^{\bullet}$ in the Watson-Crick $\mathrm{G}: \mathrm{C}$ pair (green) and the model duplex $\mathrm{GC}_{1}$ (pink). The corresponding chemical structures are illustrated in Fig. 2a. The spectrum of the deprotonated radical of dGMP is shown in blue.
$\mathrm{L}_{\mathrm{a}}$ and $\mathrm{L}_{\mathrm{b}}$ excited states of guanine (Fig. 8), respectively. ${ }^{42}$ Interestingly, in $\mathrm{GC}_{1}$, both states showed significant contribution from at least one cytosine (Fig. 8c). This feature contributed to the decrease in oscillator strength and accounted for the partial charge transfer character $(\sim 0.2$ a.u. $)$.

\section{Discussion}

Our measurements on the hydrated ejected electrons have shown that the quantum yield for one-photon ionization of $\mathrm{GC}_{5},(1.2 \pm 0.2) \times 10^{-3}$, is quite close to those found previously for alternating $\left[(1.5 \pm 0.3) \times 10^{-3}\right]^{12}$ and homopolymeric $[(1.1 \pm$ $0.3) \times 10^{-3}$ ] adenine-thymine ${ }^{11}$ duplexes, but it is four times lower than that of G-quadruplexes $\left[(4.5 \pm 0.6) \times 10^{-3}\right] .{ }^{10}$ Hence, we draw the conclusion that the simple presence of guanines within a double-stranded structure does not particularly favour electron ejection following absorption of a single photon at $266 \mathrm{~nm}$; clearly, a more complex mechanism involving more than one base is operative. It is possible that the occurrence of GG and GGG runs in duplexes can have a positive effect. Considering that even GGG tri-nucleotides tend to self-associate by Hoogsteen hydrogen bonding, giving rise four-stranded structures, ${ }^{43}$ the role of guanine stacking has to be examined for mixed GC/AT duplexes with carefully tailored base sequences.

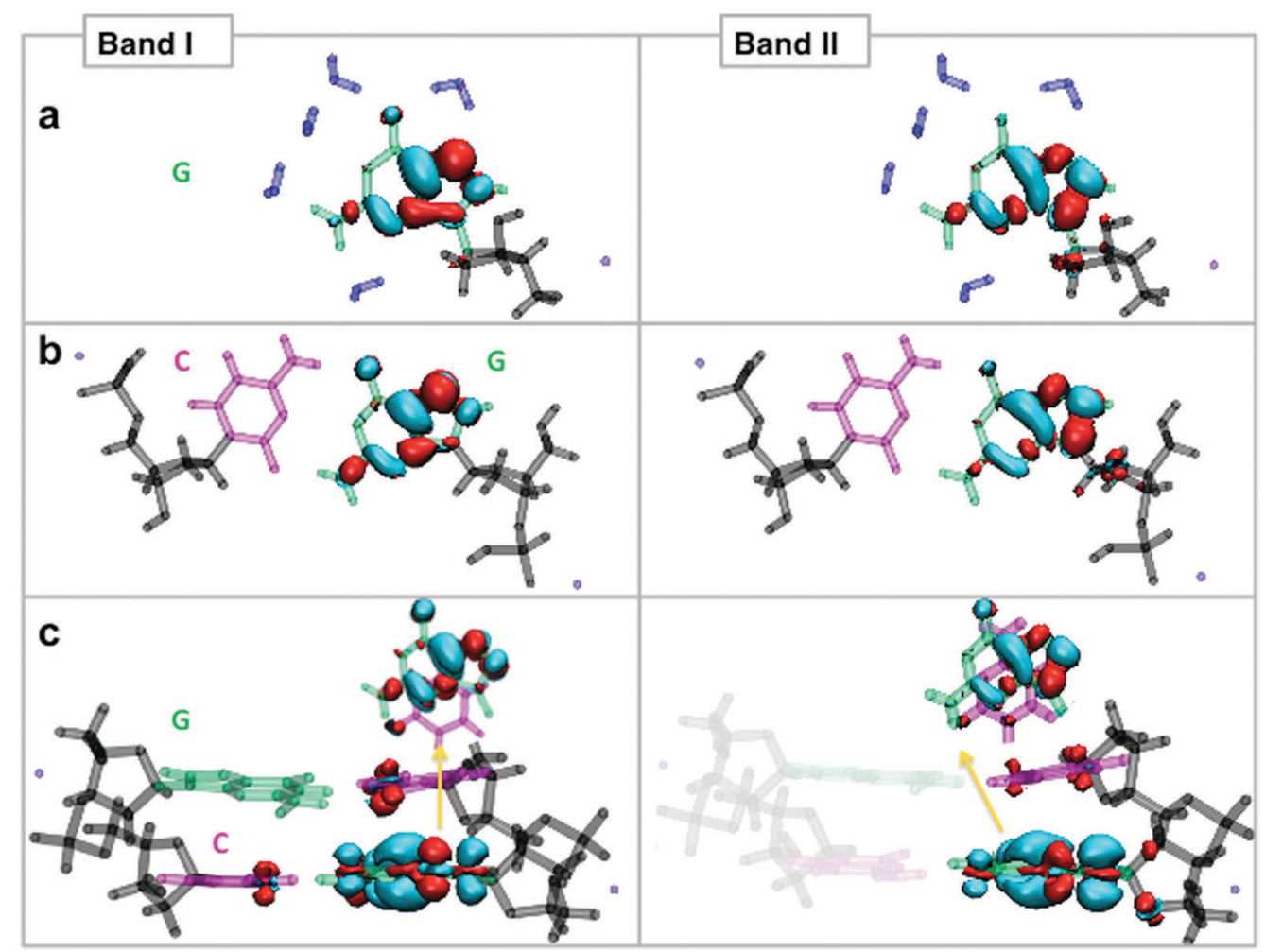

Fig. 8 Electronic density difference between the excited and ground state $\left(S_{n}-S_{0}\right)$ for the most important transitions contributing to bands I and II in Fig. 7. (a) dGMP, (b) G:C and (c) GC 1 . Green: guanine; pink: cytosine; black: deoxyribose; and red and cyan orbitals denote a decrease and increase in the electronic density, respectively. Energies and oscillator strengths for the involved transitions: Band I (a) $\mathrm{S}_{6} 3.1146 \mathrm{eV}$ and $f=0.1098$, (b) $\mathrm{S}_{8} 3.1646 \mathrm{eV}$ and $f=0.1148$ and (c) $\mathrm{S}_{12} 3.2674 \mathrm{eV}$ and $f=0.0704$ and Band II (a) $\mathrm{S}_{3} 2.1758 \mathrm{eV}$ and $f=0.0539$, (b) $\mathrm{S}_{4} 2.2084 \mathrm{eV}$ and $f=0.0298$ and (c) $\mathrm{S}_{5} 2.1322 \mathrm{eV}$ and $f=0.0170$. 
Our working hypothesis is that one-photon ionization is related to charge transfer excited states: a small part of their population can undergo charge migration and charge separation, ultimately leading to electron ejection. ${ }^{44}$ However, two-photon ionization has also been due to such excited states. ${ }^{44,45}$ Although their lifetimes in $\mathrm{GC}_{n}$ and $\mathrm{AT}_{n}$ amount only to 30 and $50 \mathrm{ps,}$ respectively, ${ }^{46-48}$ we cannot rule out that a small fraction of their population absorbs a second photon during the duration of the ns laser pulse. The two-photon yields are four times less efficient for $\mathrm{GC}_{5}$ compared to that for $\mathrm{AT}_{10}$, whereas their one-photon quantum yields are similar; this suggests that other factors such as charge separation, charge migration and interaction with water molecules acting as electron acceptors play a decisive role. An alternative explanation could be that two-photon ionization arises from HELM (high-energy emitting long-lived mixed) states, which survive on the ns time-scale ${ }^{29,49}$ and consequently have higher probability to absorb a second photon. HELM states have been detected for $\mathrm{AT}_{10}{ }^{49}$ but are hardly observable for the short GC double-stranded structures. ${ }^{50}$

Our experiments do not provide information about the bases responsible for electron ejection. Regardless, electron holes are expected to be ultimately located on the guanines, possibly after charge transport ${ }^{51-54}$ and undergo deprotonation on the ns timescale. ${ }^{38}$ It has been reported that the deprotonated guanine radicals produced in photosensitization experiments survive for hundreds of $\mathrm{ms}^{23}$ Moreover, the latter study concerning duplexes with mixed AT/GC sequences correlated a transient absorption decay occurring within a few ms with the reaction intermediate $[(8-\mathrm{OH}-\mathrm{G}): \mathrm{C}]]^{\bullet}$ leading to 8 -oxoG. ${ }^{23}$ Therefore, we examine below whether these species are present in the $\mathrm{GC}_{5}$ spectra shown in Fig. 5.

Our transient spectra shown in Fig. 5a do not indicate any clear modification over the probed timescale. The fact that the decays cannot be correctly fitted with a mono-exponential function does not necessarily mean the occurrence of more than one transient species. They may simply reflect the inhomogeneity of the system undergoing important dynamical disorder. ${ }^{55}$ We note that non-exponential decays are found for deprotonated adenine radicals. ${ }^{11}$ Another important factor to consider is that the intensity of the $\mathrm{GC}_{5}$ spectrum at $100 \mu$ s divided by the number of ejected hydrated electrons is $50 \%$ weaker compared to that of the dGMP deprotonated radical ${ }^{15}$ (Fig. 5b). Similar normalizations performed for the deprotonated radicals in adenine single strands (Fig. 2b in ref. 11), telomeric G-quadruplexes (Fig. 9 in ref. 10), and $\mathrm{AT}_{10}$ duplexes ${ }^{12}$ match the intensity of the corresponding monomer radicals within $15 \%$.

One possible reason for the $50 \%$ lower intensity of the $\mathrm{GC}_{5}$ spectrum at $100 \mu \mathrm{s}$ normalized by the concentration of ejected electrons compared to that of the deprotonated dGMP radical (Fig. 5b) is that an important population of guanine cations or even deprotonated radicals in the duplex reacts before $3 \mu \mathrm{s}$, leading to reaction products that do not absorb in the probed spectral domain.

Another possible (or additional) interpretation is provided from our computations. As a matter of fact, in the absence of reaction at shorter times, the intensity of the transient spectra normalized by the number of ejected electrons corresponds to the molar absorption coefficient of the radicals and thus, it is correlated to the oscillator strength. In the case of the systems studied previously, our theoretical calculations show that the oscillator strength of the computed radical spectra is not very different from those of the monomeric radicals, which is in perfect agreement with our normalized transient spectra. ${ }^{10-12}$ In contrast, the spectra computed in the present study for the deprotonated radicals $\left[(\mathrm{G}-\mathrm{H})^{\bullet}:(\mathrm{C}+\mathrm{H})^{+}\right]$and $[(\mathrm{G}-\mathrm{H}): \mathrm{C}]^{\bullet}$ in the model duplex $\mathrm{GC}_{1}$ are characterized by a significantly lower oscillator strength compared to that for the monomeric dGMP deprotonated radical (Fig. 6b). However, we cannot distinguish if the proton has been transferred from the position 1 of guanine to cytosine or to bulk water because the spectral features of these two radicals are quite similar (Fig. 6b).

Our experimental spectra do not exhibit the intense absorption band in the red region, which is typical of the $\left[\left(\mathrm{G}-\mathrm{H}_{2}\right): \mathrm{C}\right]^{\bullet}$ deprotonated radical despite its slightly larger computed stability $\left(0.5 \mathrm{kcal} \mathrm{mol}^{-1}\right)$ with respect to that of $[(\mathrm{G}-\mathrm{H}): \mathrm{C}]^{\bullet}$. However, we cannot rule out that a small metastable population of this radical is present before $3 \mu \mathrm{s}$ since its spectrum overlaps that of the hydrated electron. This can result in slower decay at $700 \mathrm{~nm}$ (0.6 $\mu$ s, Fig. 3a) compared to that expected for the hydrated electron alone $(0.4 \mu \mathrm{s}){ }^{11,24}$ It is also possible that this reaction is under kinetic control, with proton transfer to cytosine playing a significant role. Moreover, our calculations could have slightly overestimated the stability of $\left[\left(\mathrm{G}-\mathrm{H}_{2}\right): \mathrm{C}\right]^{\bullet}$. In the case of G-quadruplexes, for which deprotonation at the $\mathrm{NH}_{2}$ amino group is predicted to be significantly favoured over $\mathrm{NH}_{1}$ deprotonation (by $\left.2.9 \mathrm{kcal} \mathrm{mol}^{-1}\right)$, the typical spectral signature of $\left(\mathrm{G}-\mathrm{H}_{2}\right)$ radical is indeed clearly observed. ${ }^{10,56}$

Regarding the potential presence of the hydration product [(8-OH-G):C $]^{\bullet}$ in the transient absorption spectra of Fig. 5, our computations show that it exhibits a well-defined band around 450-550 nm, the oscillator strength of which is much higher than that of the guanine radical in this spectral region (Fig. 6c). However, no such band is observed in the experimental spectra of $\mathrm{GC}_{5}$. Considering the error bars in our signals, we estimate that if $[(8-\mathrm{OH}-\mathrm{G}): \mathrm{C}]^{\bullet}$ is present, its concentration on the probed timescale should be $20 \%$ lower than that of the guanine radicals.

The decay of the guanine deprotonated radicals in $\mathrm{GC}_{5}$ is somewhat slower compared to that observed for the deprotonated adenine radicals in $\mathrm{AT}_{10},{ }^{12}$ which have the corresponding halftimes of 2.5 and $2.0 \mathrm{~ms}$. In contrast, much longer decays have been reported for deprotonated guanine radicals generated by photosensitized charge transfer in duplexes. ${ }^{23}$ Interestingly, the duplexes studied in ref. 23 , contain mixed sequences with GG and GGG steps, as guanine quadruplexes for which a much slower decays are observed. ${ }^{10}$

Generally, our computed spectra provide guidance for detecting transformations of the guanine radicals in $\mathrm{GC}_{n}$. Also, they may be useful for future experiments with higher time resolution and sensitivity than those of our present experimental setup. The expected changes are shown in Fig. 9, where several differential spectra, determined as the difference between various combinations of the spectra in Fig. 6, are illustrated. The difference 


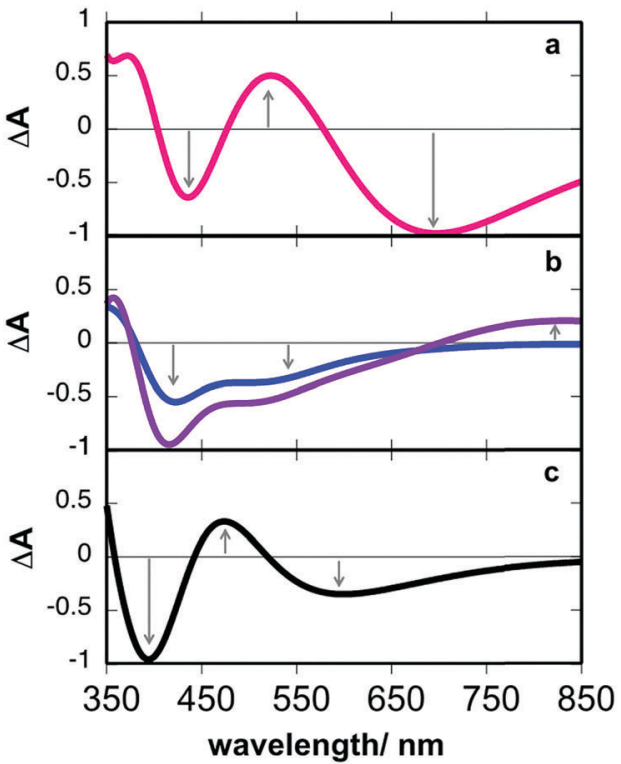

Fig. 9 Differential spectra (normalized to -1 at the maximum $\Delta A$ ) computed for (a) localization of the guanine cation, (b) deprotonation to water (violet) and to cytosine (blue) and (c) hydration of the guanine cation in $\mathrm{GC}_{1}$. Arrows correspond to the expected changes in the transient absorbance.

between the spectra of the delocalized and localized guanine cations (Fig. 9a) indicates that the localization process can be detected mainly as a decrease in the transient absorption in the red part of the visible domain. The opposite effect is expected for deprotonation to bulk water, which is consistent with the assignment reported in experimental studies, ${ }^{38}$ but no change in this spectral area can be observed for deprotonation to cytosine (Fig. 9b). Finally, hydration of the radical cation appears as a decrease at around $600 \mathrm{~nm}$ (Fig. 9c).

\section{Conclusions}

The main findings of the present study performed for alternating $\mathrm{GC}_{n}$ duplexes by nanosecond time-resolved spectroscopy and quantum chemistry calculations are as follows.

The quantum yield of one-photon ionization at $266 \mathrm{~nm}$, corresponding to energy lower than the ionization potential of the nucleobases by at least $2.3 \mathrm{eV}$, is $1.2 \times 10^{-3}$. This value represents the sum of the quantum yields corresponding to the ensemble of reaction products resulting from either radical cations or deprotonated radicals. Interestingly, it is of the same order of magnitude with that found for pyrimidine dimers ${ }^{57}$ after $254 \mathrm{~nm}$ irradiation of isolated genomic DNA although the yield of 8 -oxoG is two orders of magnitude lower. ${ }^{58,59}$ The complex processes leading to electron ejection, possibly related to excited charge transfer states, remain to be assessed.

The main species present in the duplex after $3 \mu \mathrm{s}$ are identified as deprotonated guanine radicals with the proton from position 1 being transferred either to bulk water or to cytosine. The absorption of both these radicals in the duplex differs from that of the monomeric radical by the intensity in the visible domain, which is significantly lower. Their population in
$\mathrm{GC}_{5}$ decreases by $50 \%$ at $2.5 \mathrm{~ms}$ and only $10 \%$ of it survives at $20 \mathrm{~ms}$.

The reaction intermediate resulting from the hydration of the guanine radical cation, which gives rise to 8-oxoG, has not been detected. Its contribution to the spectra determined on the ms timescale is estimated to be lower than $20 \%$.

Our calculations showed that not only base-pairing but also base-stacking affects the spectra of guanine radicals in duplexes. The study of duplexes containing both adenine-thymine and guanine-cytosine base pairs, including GG and GGG steps, should bring further insights on both the ionization process by low energy photons and the behaviour of the generated radicals.

\section{Conflicts of interest}

There are no conflicts to declare.

\section{Acknowledgements}

The authors thank the CNR (Progetto Bilaterale CNR/CNRS PICS 2015), the Université Paris Saclay (programme D’Alambert 2016, No. 10751), the French National Agency for Research (ANR-12-BS08-0001-01) and the LABEX-PALM (OSPEG project) for financial support. This work was performed using HPC resources from GENCI-IDRIS (Grant 2017-A0030810262).

\section{Notes and references}

1 L. P. Candeias, P. O’Neill, G. D. D. Jones and S. Steenken, Int. J. Radiat. Biol., 1992, 61, 15-20.

2 J. Cadet, J. R. Wagner, V. Shafirovich and N. E. Geacintov, Int. J. Radiat. Biol., 2014, 90, 423-432.

3 J. C. Sutherland and K. P. Griffin, Radiat. Res., 1981, 86, 399-410.

4 A. Banyasz, I. Vayá, P. Changenet-Barret, T. Gustavsson, T. Douki and D. Markovitsi, J. Am. Chem. Soc., 2011, 133, 5163-5165.

5 C. A. Schroeder, E. Pluharova, R. Seidel, W. P. Schroeder, M. Faubel, P. Slavicek, B. Winter, P. Jungwirth and S. E. Bradforth, J. Am. Chem. Soc., 2015, 137, 201-209.

6 C. E. Crespo-Hernandez and R. Arce, J. Phys. Chem. B, 2003, 107, 1062-1070.

7 S. Marguet, D. Markovitsi and F. Talbot, J. Phys. Chem. B, 2006, 110, 11037-11039.

8 V. Gabelica, F. Rosu, T. Tabarin, C. Kinet, R. Antoine, M. Broyer, E. De Pauw and P. Dugourd, J. Am. Chem. Soc., 2007, 129, 4706-4713.

9 M. Gomez-Mendoza, A. Banyasz, T. Douki, D. Markovitsi and J. L. Ravanat, J. Phys. Chem. Lett., 2016, 7, 3945-3948.

10 A. Banyasz, L. Martinez-Fernandez, C. Balty, M. Perron, T. Douki, R. Improta and D. Markovitsi, J. Am. Chem. Soc., 2017, 139, 10561-10568.

11 A. Banyasz, T. Ketola, A. Muñoz-Losa, S. Rishi, A. Adhikary, M. D. Sevilla, L. Martinez-Fernandez, R. Improrta and D. Markovitsi, J. Phys. Chem. Lett., 2016, 7, 3949-3953.

12 A. Banyasz, T. Ketola, L. Martínez-Fernández, I. Improta and D. Markovitsi, Faraday Discuss., 2018, 181-197. 
13 L. P. Candeias and S. Steenken, J. Am. Chem. Soc., 1992, 114, 699-704.

14 L. P. Candeias and S. Steenken, J. Am. Chem. Soc., 1993, 115, 2437-2440.

15 L. P. Candeias and S. Steenken, J. Am. Chem. Soc., 1989, 111, 1094-1099.

16 S. Steenken, Chem. Rev., 1989, 89, 503-520.

17 A. Adhikary, D. Khanduri and M. D. Sevilla, J. Am. Chem. Soc., 2009, 131, 8614-8619.

18 J. Cadet, T. Douki and J. L. Ravanat, Acc. Chem. Res., 2008, 41, 1075-1083.

19 L. I. Shukla, A. Adhikary, R. Pazdro, D. Becker and M. D. Sevilla, Nucleic Acids Res., 2004, 32, 6565-6574.

20 J. L. Ravanat, C. Saint-Pierre and J. Cadet, J. Am. Chem. Soc., 2003, 125, 2030-2031.

21 R. Misiaszek, C. Crean, A. Joffe, N. E. Geacintov and V. Shafirovich, J. Biol. Chem., 2004, 279, 32106-32115.

22 J. Cadet and K. J. A. Davies, Free Radicals Biol. Med., 2017, 107, 2-12.

23 Y. Rokhlenko, J. Cadet, N. E. Geacintov and V. Shafirovich, J. Am. Chem. Soc., 2014, 136, 5956-5962.

24 A. Banyasz, T. Ketola, L. Martinez-Fernandez, R. Improta and D. Markovitsi, Faraday Discuss., 2018, 207, 181-197.

25 Y. Zhao and D. G. Truhlar, Acc. Chem. Res., 2008, 41, 157-167.

26 L. Biemann, S. A. Kovalenko, K. Kleinermanns, R. Mahrwald, M. Markert and R. Improta, J. Am. Chem. Soc., 2011, 133, 19664-19667.

27 Y. Zhang, K. de La Harpe, A. A. Beckstead, R. Improta and B. Kohler, J. Am. Chem. Soc., 2015, 137, 7059-7062.

28 Y. Zhang, K. de La Harpe, A. A. Beckstead, L. MartinezFernandez, R. Improta and B. Kohler, J. Phys. Chem. Lett., 2016, 7, 950-954.

29 M. Huix-Rotllant, J. Brazard, R. Improta, I. Burghardt and D. Markovitsi, J. Phys. Chem. Lett., 2015, 6, 2247-2251.

30 J. Cerezo, L. Martinez-Fernandez, R. Improta and F. Santoro, Theor. Chem. Acc., 2016, 135, 221.

31 L. Martinez-Fernadez and R. Importa, Faraday Discuss., 2018, 207, 199-216.

32 S. Miertus, E. Scrocco and J. Tomasi, Chem. Phys., 1981, 55, 117-129.

33 J. Tomasi, B. Mennucci and R. Cammi, Chem. Rev., 2005, 105, 2999-3093.

34 M. J. Frisch, G. W. Trucks, H. B. Schlegel, G. E. Scuseria, M. A. Robb, J. R. Cheeseman, G. Scalmani, V. Barone, B. Mennucci, G. A. Petersson, H. Nakatsuji, M. Caricato, X. Li, H. P. Hratchian, A. F. Izmaylov, J. Bloino, G. Zheng, J. L. Sonnenberg, M. Hada, M. Ehara, K. Toyota, R. Fukuda, J. Hasegawa, M. Ishida, T. Nakajima, Y. Honda, O. Kitao, H. Nakai, T. Vreven, J. A. Montgomery, J. J. E. Peralta, F. Ogliaro, M. Bearpark, J. J. Heyd, E. Brothers, K. N. Kudin, V. N. Staroverov, R. Kobayashi, J. Normand, K. Raghavachari, A. Rendell, J. C. Burant, S. S. Iyengar, J. Tomasi, M. Cossi, N. Rega, J. M. Millam, M. Klene, J. E. Knox, J. B. Cross, V. Bakken, C. Adamo, J. Jaramillo, R. Gomperts, R. E. Stratmann, O. Yazyev, A. J. Austin, R. C. Cammi, C. Pomelli, J. W. Ochterski, R. L. Martin, K. Morokuma, V. G. Zakrzewski, G. A. Voth, P. Salvador, J. J. Dannenberg,
S. Dapprich, A. D. Daniels, O. Farkas, J. B. Foresman, J. V. Ortiz, J. Cioslowski and D. J. Fox, Gaussian 09, revision A.02, Gaussian Inc., Wallingford CT, 2009.

35 F. J. A. Ferrer, J. Cerezo, E. Stendardo, R. Improta and F. Santoro, J. Chem. Theory Comput., 2013, 9, 2072-2082.

36 F. Torche and J. L. Marignier, J. Phys. Chem. B, 2016, 120, 7201-7206.

37 C. von Sonntag, Free-Radical-Induced DNA damage and its Repair, Springer-Verlag, Berlin, Heildelberg, 2006.

38 K. Kobayashi and S. Tagawa, J. Am. Chem. Soc., 2003, 125, 10213-10218.

39 A. Kumar and M. D. Sevilla, J. Phys. Chem. B, 2009, 113, 11359-11361.

40 A. Adhikary, A. Kumar, S. A. Munafo, D. Khanduri and M. D. Sevilla, Phys. Chem. Chem. Phys., 2010, 12, 5353-5368.

41 C. Chatgilialoglu, C. Caminal, A. Altieri, G. C. Vougioukalakis, Q. G. Mulazzani, T. Gimisis and M. Guerra, J. Am. Chem. Soc., 2006, 128, 13796-13805.

42 R. Improta, F. Santoro and L. Blancafort, Chem. Rev., 2016, 116, 3540-3593.

43 D. Markovitsi, T. Gustavsson and A. Sharonov, Photochem. Photobiol., 2004, 79, 526-530.

44 V. e. a. Bhat, Faraday Discuss., 2018, 207, 283-306.

45 L. Colon, C. E. Crespo-Hernandez, R. Oyola, C. Garcia and R. Arce, J. Phys. Chem. B, 2006, 110, 15589-15596.

46 C. E. Crespo-Hernández, B. Cohen and B. Kohler, Nature, 2005, 436, 1141-1144.

47 Y. Y. Zhang, K. de La Harpe, A. A. Beckstead, L. MartinezFernandez, R. Improta and B. Kohler, J. Phys. Chem. Lett., 2016, 7, 950-954.

48 G. W. Doorley, D. A. McGovern, M. W. George, M. Towrie, A. W. Parker, J. M. Kelly and S. J. Quinn, Angew. Chem., Int. Ed., 2009, 48, 123-127.

49 I. Vayá, J. Brazard, M. Huix-Rotllant, A. Thazhathveetil, F. Lewis, T. Gustavsson, I. Burghardt, R. Improta and D. Markovitsi, Chem. - Eur. J., 2016, 22, 4904-4914.

50 J. Brazard, A. Thazhathveetil, I. Vayá, F. Lewis, T. Gustavsson and D. Markovitsi, Photochem. Photobiol. Sci., 2013, 12, 1453-1459.

51 J. C. Genereux and J. K. Barton, Chem. Rev., 2010, 110, 1642-1662.

52 K. Kawai and T. Majima, Acc. Chem. Res., 2013, 46, 2616-2625. 53 N. Renaud, M. A. Harris, A. P. N. Singh, Y. A. Berlin, M. A. Ratner, M. R. Wasielewski, F. D. Lewis and F. C. Grozema, Nat. Chem., 2016, 8, 1015-1021.

54 S. Kanvah, J. Joseph, G. B. Schuster, R. N. Barnett, C. L. Cleveland and U. Landman, Acc. Chem. Res., 2010, 43, 280-287.

55 E. Emanuele, K. Zakrzewska, D. Markovitsi, R. Lavery and P. Millie, J. Phys. Chem. B, 2005, 109, 16109-16118.

56 L. D. Wu, K. H. Liu, J. L. Jie, D. Song and H. M. Su, J. Am. Chem. Soc., 2015, 137, 259-266.

57 T. Douki, J. Photochem. Photobiol., B, 2006, 82, 45-52.

58 J. Cadet, S. Mouret, J.-L. Ravanat and T. Douki, Photochem. Photobiol., 2012, 88, 1048-1065.

59 H. Ikehata, T. Mori, T. Douki, J. Cadet and M. Yamamoto, Photochem. Photobiol. Sci., 2018, 17, 404-413. 